\title{
No energy compensation at the meal following exercise in dietary restrained and unrestrained women
}

\author{
Anne Lluch*, Neil A. King and John E. Blundell \\ BioPsychology Group, School of Psychology, University of Leeds, Leeds, UK
}

(Received 13 July 1999 - Revised 23 December 1999 - Accepted 7 January 2000)

\begin{abstract}
The objective of this investigation was to compare the acute effects of exercise and diet manipulations on energy intake, between dietary restrained and unrestrained females. Comparisons of two studies using an identical $2 \times 2$ repeated-measures design (level of activity (rest or exercise) and lunch type (high-fat or low-fat)) including thirteen dietary unrestrained and twelve restrained females were performed. Energy expenditure during the rest session was estimated and the energy cost of exercise was measured by indirect calorimetry. Relative energy intake was calculated by subtracting the energy expenditure of the exercise session from the energy intake of the test meal. Post-meal hedonic ratings were completed after lunch. Energy intake and relative energy intake increased during high-fat conditions compared with the low-fat, independently of exercise $(P<0 \cdot 001)$. There was a positive relationship between dietary restraint scores and energy intake or relative energy intake in the rest conditions only $(r 0.54, P<0.01)$. The decrease of relative energy intake between the rest and exercise conditions was higher in restrained than in unrestrained eaters $(P<0 \cdot 01)$. These results confirm that a high-fat diet reversed the energy deficit due to exercise. There was no energy compensation in response to an acute bout of exercise during the following meal. In restrained eaters, exercise was more effective in creating an energy deficit than in unrestrained eaters. Exercise may help restrained eaters to maintain control over appetite.
\end{abstract}

Physical activity: Energy intake: Dietary restraint

Restrained eating has been defined as the tendency to restrict food intake consciously in order to prevent weight gain or to promote weight loss (Herman \& Mack, 1975; Herman \& Polivy, 1975). Dieting, however, implies a restriction of food intake entirely undertaken in order to promote weight loss. Restrained eaters, lean or obese, stop eating not in response to satiety but because they have reached a cognitively-set limit. An association between dietary restraint and reduced energy intake has often been reported in adults (van Strien et al. 1986; Wardle \& Beales, 1987; Laessle et al. 1989; Tuschl et al. 1990; Klesges et al. 1992; French et al. 1994; de Castro, 1995; Green \& Blundell, 1996), adolescents (Wardle et al. 1992) and children (Hill \& Robinson, 1991). However, a central hypothesis of the dietary restraint theory is that the intent to diet may be disrupted by certain events such as preloads of food, alcohol and dysphoric emotions (for review see Ruderman, 1986). This phenomenon is related to the disinhibition of cognitive control of eating behaviour and it leads to episodes of overeating. Weight fluctuations may be experienced as a result of these alternate periods of restrained and uncontrolled eating (Hill et al. 1995), and therefore make the attempt to control body weight unsuccessful.

Physical activity can be considered as a method of creating an energy deficit in order to control body weight, providing that there is no or incomplete energy compensation following exercise. When assessing the possibility of energy compensation in response to exercise, the potential theoretical differences between restrained and unrestrained eaters have been previously highlighted as an important consideration (Hill et al. 1995). According to this model, lean unrestrained individuals (those who do not diet and do not cognitively control food intake) would respond to increased physical activity by increasing their food intake. Restrained individuals who are currently dieting might either choose to maintain constant food intake or to decrease it in order to obtain or accelerate weight loss. If the restrained individuals are not currently dieting, it would be unlikely to observe changes of energy intake in response to increased physical activity unless subjects are responsive to cues of hunger and satiety.

In order to test the hypotheses described in this model, the aim of this present paper was to compare the short-term 
effects of exercise and diet composition on appetite control between dietary restrained and unrestrained females. The data needed to perform these analyses were available from two separate studies with identical designs, conducted in the same laboratory (King et al. 1996; Lluch et al. 1998). In the present paper, the effects of exercise on energy intake and food hedonic ratings are addressed by re-analysis of these previously collected data. In the rest conditions (which should be comparable to free-living and 'normal life' situations), energy intake was expected to be lower in restrained than in unrestrained females. After exercise, two hypotheses are suggested. Either reduced energy intake could be accentuated in restrained eaters or alternatively, exercise could relax the control of food intake in these subjects, leading to increased energy intake. Changes in the perception of food hedonics after exercise could possibly have an additional effect.

\section{Methods}

The data used in this study were available from two previous investigations carried out in unrestrained and restrained females (King et al. 1996; Lluch et al. 1998). Details regarding the methods have been previously described in the corresponding publications.

\section{Subjects}

Subjects were recruited from the student population of Leeds University, Leeds, UK, to complete the study. Data were collected from twenty-five normal-weight, regularly exercising females, defined as unrestrained or restrained eaters by the Three Factor Eating Questionnaire (Stunkard $\&$ Messick, 1985). Restrained subjects scored strictly above 10 on the restraint scale. All subjects from both groups were regular exercisers (at least three sessions of $30 \mathrm{~min}$ of moderate to vigorous exercise per week), non-smokers and were not taking any medication. Heights and weights were measured at the beginning of the study. The experimental protocol was approved by the Psychology Department Ethical Committee at Leeds University. Subjects gave written consent and were paid for participation.

\section{Design and procedure}

The study was designed to assess the effects of a bout of high-intensity exercise followed by a free-selection lunch (varying in macronutrient composition) on energy intake and food hedonic ratings. A $2 \times 2$ repeated-measures design was used, with subjects acting as their own control. The level of activity (rest or exercise) and the lunch type (low-fat or high-fat) were the repeated factors. Individuals were assigned to each of the conditions, in a counterbalanced order, with 1 week separating each experimental day. Subjects were asked to attend the Human Appetite Research Unit in the morning of each experimental day to be provided with a standard breakfast. Quantities eaten at the first occasion were served at the three following ones, during which subjects were asked to eat all the foods provided. Subjects returned $2 \mathrm{~h} 45 \mathrm{~min}$ after the beginning of the breakfast to undergo one of the four following treatments:
(1) Rest-low fat (Rest-LF). Subjects remained seated for approximately $50 \mathrm{~min}$ in an individual room and were allowed to read and/or write, after which they were provided with a low-fat test lunch (mean food quotient $>0.85$ ); (2) Rest-high fat (Rest-HF). Subjects remained seated for approximately $50 \mathrm{~min}$ in an individual room and were allowed to read and/or write, after which they were provided with a high-fat test lunch (mean food quotient $<0 \cdot 85$ ); (3) Exercise-low fat $(\mathrm{Ex}-\mathrm{LF})$. Subjects cycled for $50 \mathrm{~min}$ at $70 \%$ of their $\mathrm{V}_{\mathrm{O}_{2} \max }$, after which they were provided with a low-fat test lunch (mean food quotient $>0 \cdot 85$ ); (4) Exercise-high fat (Ex-HF). Subjects cycled for $50 \mathrm{~min}$ at $70 \%$ of their $\mathrm{V}_{\mathrm{O}_{2} \max }$, after which they were provided with a high-fat test lunch (mean food quotient $<0 \cdot 85$ ).

Subjects were instructed to refrain from heavy exercise and from consuming alcohol $1 \mathrm{~d}$ prior to each experimental day and to keep habits and activities as constant as possible during the course of the study.

\section{Physical activity}

During the exercise sessions, indirect calorimetry was used to collect expired air samples every $10 \mathrm{~min}$ in order to calculate energy expenditure and to confirm that subjects were working at the required exercise intensity $\left(70 \% \mathrm{~V}_{\mathrm{O}_{2} \max }\right)$. Two indirect calorimetry techniques were used to measure the energy cost of exercise. A Douglas bag system and an online (Vmax 29, SensorMedics Corporation, Yorba Linda, CA, USA) system were used for the unrestrained and restrained subjects respectively. A validation study had been previously carried out in five healthy males on an ergometer at work rates ranging between 40 and $160 \mathrm{~W}$. Correlations for the minute ventilation, the $\mathrm{CO}_{2}$ output, and the $\mathrm{O}_{2}$ uptake were 0.998, 0.997 and 0.993 respectively (Storer et al. 1995). On the experimental days, each subject was asked to refrain from prescribed exercise but was allowed to continue with habitual activities (e.g. walking to and from work and climbing stairs). Resting energy expenditure was estimated for each subject, using the following equation: REE $(\mathrm{kJ})=4.19 \mathrm{~kJ} / \mathrm{kg}$ body weight per h (Ainsworth et al. 1993).

\section{Lunch test meal}

After the end of the exercise or rest sessions, subjects were asked to stay in an individual room within the Appetite Research Unit where their lunch was served ad libitum. Each test meal consisted of a choice of seven foods. For the low-fat lunch, sandwiches (cheese or tuna), coleslaw, breadsticks, pizza, fruit yoghurt, swiss roll and jaffa cakes were offered. The high-fat lunch consisted of a choice of sandwiches (cheese or tuna), coleslaw, crisps, vegetarian quiche, fruit fool, Viennese whirls and chocolate wafer biscuits. The list of all the foods, their energy and nutritional contents, food quotient and served portions have been previously detailed (Lluch et al. 1998). Subjects were informed that they could eat as much or as little as they wanted within a $30 \mathrm{~min}$ period and could select any of the food items. Subjects were not allowed to consume any foods in between breakfast and lunch but were allowed to have one drink (coffee or tea without milk and sugar, or water). 


\section{Energy and macronutrient intake}

Energy and macronutrient intakes were calculated by weighing the food before and after consumption (to the nearest $0 \cdot 1 \mathrm{~g}$ ) and using manufacturer's values and a computerised version of food tables (Compeat 4.0, Nutrition Systems, London, UK). The factors used for conversion of nutrients into energy values $(\mathrm{kJ})$ were $16 \cdot 7,37 \cdot 7$ and $15 \cdot 7$ for protein, fat and carbohydrate respectively. In order to investigate the energy compensation after exercise, it is important to examine the effects of exercise with respect to absolute (energy intake during the test meal) and relative energy intake (energy intake accounting for energy expenditure) (King et al. 1997). Therefore, the relative energy intake was calculated for lunch by subtracting the measured energy expenditure during the exercise (and estimated during the rest) session from the energy intake during the test meal (lunch).

\section{Post-meal food hedonic ratings}

After lunch, subjects were asked to complete post-meal ratings on $100 \mathrm{~mm}$ visual analogue scales, including palatability, tastiness, pleasantness. Questions were as follows: 'How palatable/tasty/pleasant was this meal?' with 'not at all' and 'extremely' at both extremities of the lines.

\section{Statistical analyses}

Data were analysed using SPSS (Windows Version 6.1; Chicago, IL, USA). Repeated-measures two-way ANOVA was used to analyse nutritional data and post-meal hedonic ratings with 'level of activity' (rest or exercise) and 'lunch type' (low- or high-fat) as the within-subject factors and 'group' (restrained or unrestrained eaters) as the between-subject factor. Post-hoc $t$ tests were used to analyse differences between pairs of means. Pearson correlation analysis was performed to assess the association between nutritional data and scores of dietary restraint or food hedonic ratings, for each condition. All tests were conducted at the $5 \%$ probability level.

\section{Results \\ Subjects}

Descriptive characteristics of the subjects are presented in Table 1 . Ten out of the twelve dietary restrained females were not currently dieting. Seven dietary restrained subjects were more likely to use both exercise and dietary restraint to control their body shape or weight, two exercise only and three dietary restraint only. There were no significant differences between the two groups of restrained and unrestrained females for age, BMI and body fat. As expected, restraint scores were significantly higher in restrained than in unrestrained eaters $(t 8 \cdot 0, P<0 \cdot 001)$. For each group, mean energy cost of exercise, exercise intensity and RQ did not differ significantly between the two exercise sessions (King et al. 1996; Lluch et al. 1998). However, maximal $\mathrm{O}_{2}$ consumption $\left(\mathrm{V}_{\mathrm{O}_{2} \max }\right)$ and average energy cost of the two exercise sessions were significantly lower in unrestrained than in restrained females $(t 2.6, P<0.05, t 3.5, P<0.01$ respectively). For this reason, although results of energy intake will be presented, the interest will be focused on analyses of relative energy intake which take into account the energy expended.

\section{Energy and macronutrient intake}

Energy and macronutrient intake during each of the four test lunches are shown in Table 2. There was a main effect of lunch type on energy intake $(F[1,23] 111 \cdot 2, P<0.001)$, with energy intake increased in both high-fat conditions compared with the low-fat (Fig. 1(a)). There was a level of activity $\times$ group interaction on energy intake, but this failed to reach the level of significance $(F[1,23] 3 \cdot 2, P=0.08)$ : unrestrained subjects increased their energy intakes after exercise, whereas in restrained eaters energy intakes tended to decrease (Fig. 2(a)). Post-hoc tests indicated that restrained subjects ate significantly more than unrestrained eaters in the rest condition $(t 2.6, P<0.05)$ but not in the exercise condition. This difference was confirmed by a significant positive relationship between restraint scores and energy intake (average of both low-fat and high-fat conditions $)$ in the rest $(r 0.54, P<0.01)$ but not in the exercise conditions $(r 0 \cdot 09, \mathrm{NS})$. When the exercise-induced energy expended was controlled for, there was a significant effect of lunch type $(F[1,23] 112 \cdot 7, P<0 \cdot 001)$ (Fig. 1(b)), exercise $(F[1,23] 100 \cdot 7, P<0.001)$ and a level of activity $\times$ group interaction $(F[1,23] 8 \cdot 6, P<0 \cdot 01)$ on relative energy intake: exercise decreased relative energy intake when compared to rest and this difference was higher in restrained than in unrestrained subjects (Fig. 2(b)).

There was a significant effect of lunch type on weight of food eaten $(F[1,23] 6 \cdot 8, P<0.05)$, with more food eaten during the low-fat than the high-fat conditions. A group $\times$ lunch type interaction on weight of food eaten failed to reach significance $(F[1,23] 3 \cdot 2, P=0 \cdot 09)$ : unrestrained

Table 1. Descriptive characteristics of the subjects

(Mean values and standard deviations)

\begin{tabular}{|c|c|c|c|c|c|c|c|c|c|c|c|c|c|}
\hline & \multirow[b]{2}{*}{$n$} & \multicolumn{2}{|c|}{$\begin{array}{c}\text { Age } \\
\text { (years) }\end{array}$} & \multicolumn{2}{|c|}{$\begin{array}{c}\mathrm{BMI} \\
\left(\mathrm{kg} / \mathrm{m}^{2}\right)\end{array}$} & \multicolumn{2}{|c|}{$\begin{array}{l}\text { Body fat } \\
(\%)\end{array}$} & \multicolumn{2}{|c|}{$\begin{array}{l}\text { Restraint } \\
\text { score }^{*}\end{array}$} & \multicolumn{2}{|c|}{$\begin{array}{c}\mathrm{V}_{\mathrm{O}_{2} \max } \\
(\mathrm{ml} / \mathrm{kg} \text { per min) }\end{array}$} & \multicolumn{2}{|c|}{$\begin{array}{l}\text { Energy cost of } \\
\text { exercise }(\mathrm{kJ})\end{array}$} \\
\hline & & Mean & SD & Mean & SD & Mean & SD & Mean & SD & Mean & SD & Mean & SD \\
\hline Unrestrained eaters & 13 & $22 \cdot 6$ & $2 \cdot 3$ & 21.9 & 1.6 & 24.7 & 3.0 & 4.4 & 3.0 & 37.0 & 3.3 & 1455 & 213 \\
\hline Restrained eaters & 12 & $21 \cdot 7$ & $2 \cdot 2$ & $22 \cdot 6$ & 1.9 & $25 \cdot 6$ & $2 \cdot 2$ & $13 \cdot 3$ & 2.5 & 41.0 & 4.4 & 1772 & 242 \\
\hline
\end{tabular}

* Measured using the Three Factor Eating Questionnaire (Stunkard \& Messick, 1985); restrained subjects scored $>10$ on the restraint scale. 
Table 2. Energy intake (EI), relative El and nutrient intakes (lunch) on each of the four experimental days, in thirteen unrestrained (U) and twelve restrained $(R)$ eaters*

(Mean values and standard deviations)

\begin{tabular}{|c|c|c|c|c|c|c|c|c|c|c|c|c|c|c|c|c|}
\hline & \multicolumn{4}{|c|}{ Rest-LF } & \multicolumn{4}{|c|}{ Rest-HF } & \multicolumn{4}{|c|}{ Ex-LF } & \multicolumn{4}{|c|}{ Ex-HF } \\
\hline & \multicolumn{2}{|l|}{$U$} & \multicolumn{2}{|l|}{$\mathrm{R}$} & \multicolumn{2}{|c|}{$U$} & \multicolumn{2}{|c|}{$\mathrm{R}$} & \multicolumn{2}{|c|}{ U } & \multicolumn{2}{|c|}{$\mathrm{R}$} & \multicolumn{2}{|c|}{$U$} & \multicolumn{2}{|l|}{$\mathrm{R}$} \\
\hline & Mean & SD & Mean & SD & Mean & SD & Mean & SD & Mean & SD & Mean & SD & Mean & SD & Mean & SD \\
\hline $\begin{array}{l}\text { Energy intake } \\
(\mathrm{kJ})\end{array}$ & 2725 & 548 & 3231 & 548 & 4477 & 782 & 5121 & 986 & 2993 & 506 & 2934 & 585 & 4878 & 995 & 5171 & 1141 \\
\hline $\begin{array}{l}\text { Lunch relative } \\
\text { El }(\mathrm{kJ}) \dagger\end{array}$ & 2525 & 539 & 3018 & 539 & 4276 & 773 & 4912 & 982 & 1534 & 451 & 1154 & 493 & 3423 & 1041 & 3407 & 995 \\
\hline $\begin{array}{l}\text { Weight of food } \\
\text { eaten }(\mathrm{g})\end{array}$ & 356 & 81 & 478 & 137 & 287 & 68 & 442 & 92 & 427 & 196 & 456 & 144 & 309 & 79 & 456 & 110 \\
\hline $\begin{array}{l}\text { Protein intake } \\
\text { (\% of energy) }\end{array}$ & $18 \cdot 9$ & $2 \cdot 3$ & $18 \cdot 3$ & $2 \cdot 9$ & $9 \cdot 1$ & 1.5 & $9 \cdot 1$ & 1.6 & $18 \cdot 6$ & 3.1 & 18.9 & $2 \cdot 3$ & $9 \cdot 1$ & 1.9 & $9 \cdot 2$ & $2 \cdot 3$ \\
\hline $\begin{array}{l}\text { Fat intake } \\
\text { (\% of energy) }\end{array}$ & $20 \cdot 7$ & 3.9 & $25 \cdot 0$ & $2 \cdot 2$ & $65 \cdot 2$ & 4.8 & $65 \cdot 2$ & $7 \cdot 0$ & 20.5 & 3.4 & $25 \cdot 0$ & $1 \cdot 8$ & 65.8 & $5 \cdot 4$ & $64 \cdot 7$ & 5.9 \\
\hline $\begin{array}{l}\text { Carbohydrate } \\
\text { intake } \\
\text { (\% of energy) }\end{array}$ & 60.5 & 4.8 & $56 \cdot 7$ & 4.7 & $24 \cdot 7$ & 2.9 & $25 \cdot 7$ & $6 \cdot 1$ & $60 \cdot 9$ & $5 \cdot 2$ & $56 \cdot 1$ & 3.5 & $24 \cdot 3$ & $2 \cdot 7$ & $26 \cdot 1$ & $4 \cdot 8$ \\
\hline
\end{tabular}

Rest-LF, rest-low fat; Rest-HF, rest-high fat; Ex-LF, exercise-low fat; Ex-Hf, exercise-high fat.

${ }^{*}$ Restraint scores were calculated using the Three Factor Eating Questionnaire (Stunkard \& Messick, 1985); restrained subjects scored >10 on the restraint scale. † Relative energy intake = energy intake during the test meal - energy expenditure (measured during exercise session and estimated during rest session).
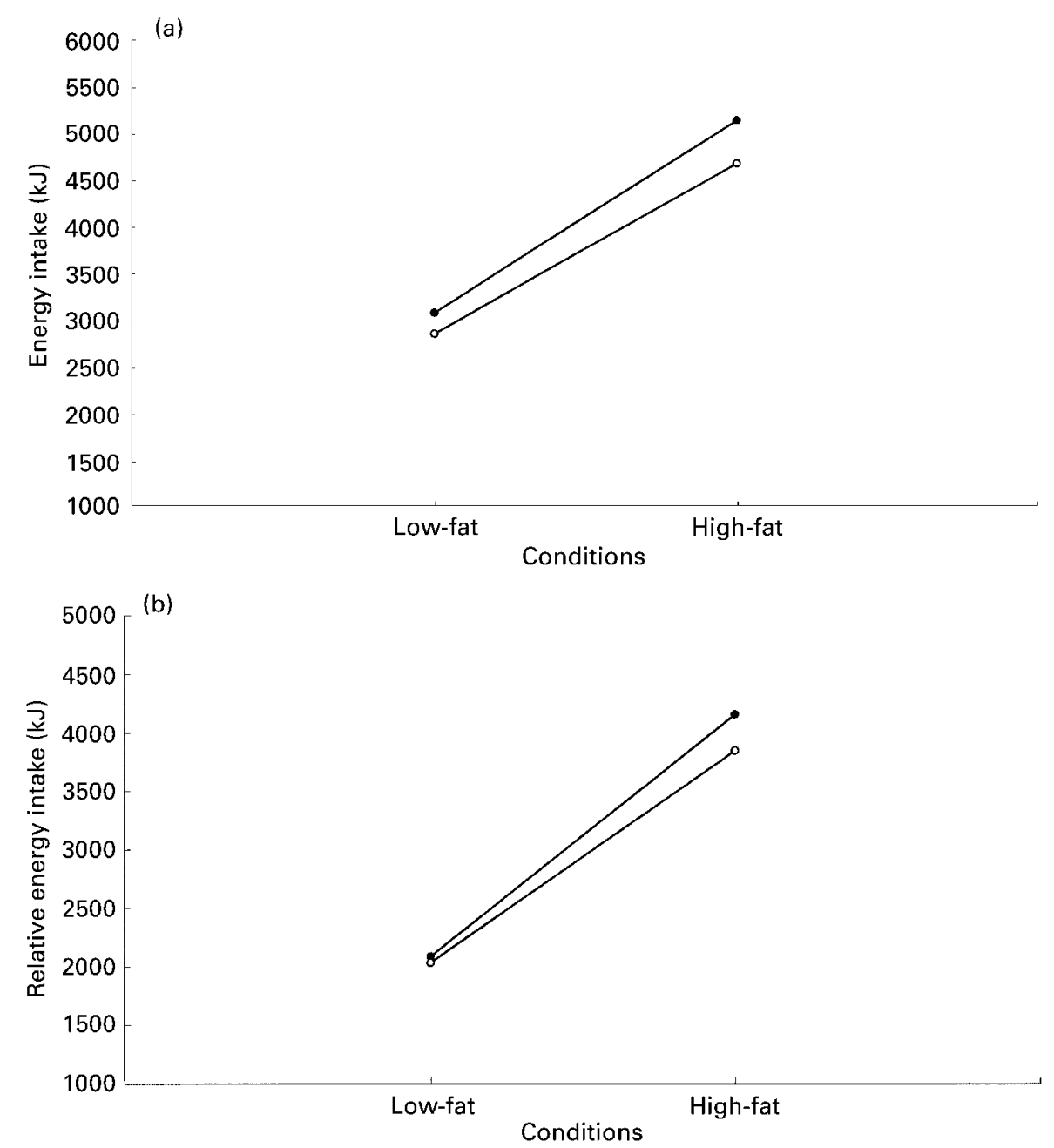

Fig. 1. Effect of lunch type on (a) energy intake and (b) relative energy intake (average of rest and exercise conditions) in twelve restrained ( $\bullet$ ) and thirteen unrestrained $(O)$ eaters. Restraint scores were calculated using the Three Factor Eating Questionnaire (Stunkard \& Messick, 1985); restrained eaters scored $>10$ on the restraint scale. For details of low-fat and high-fat conditions see pp. 220-221. Relative energy intake=energy intake during the test meal-energy expenditure (measured during exercise session and estimated during rest session). 

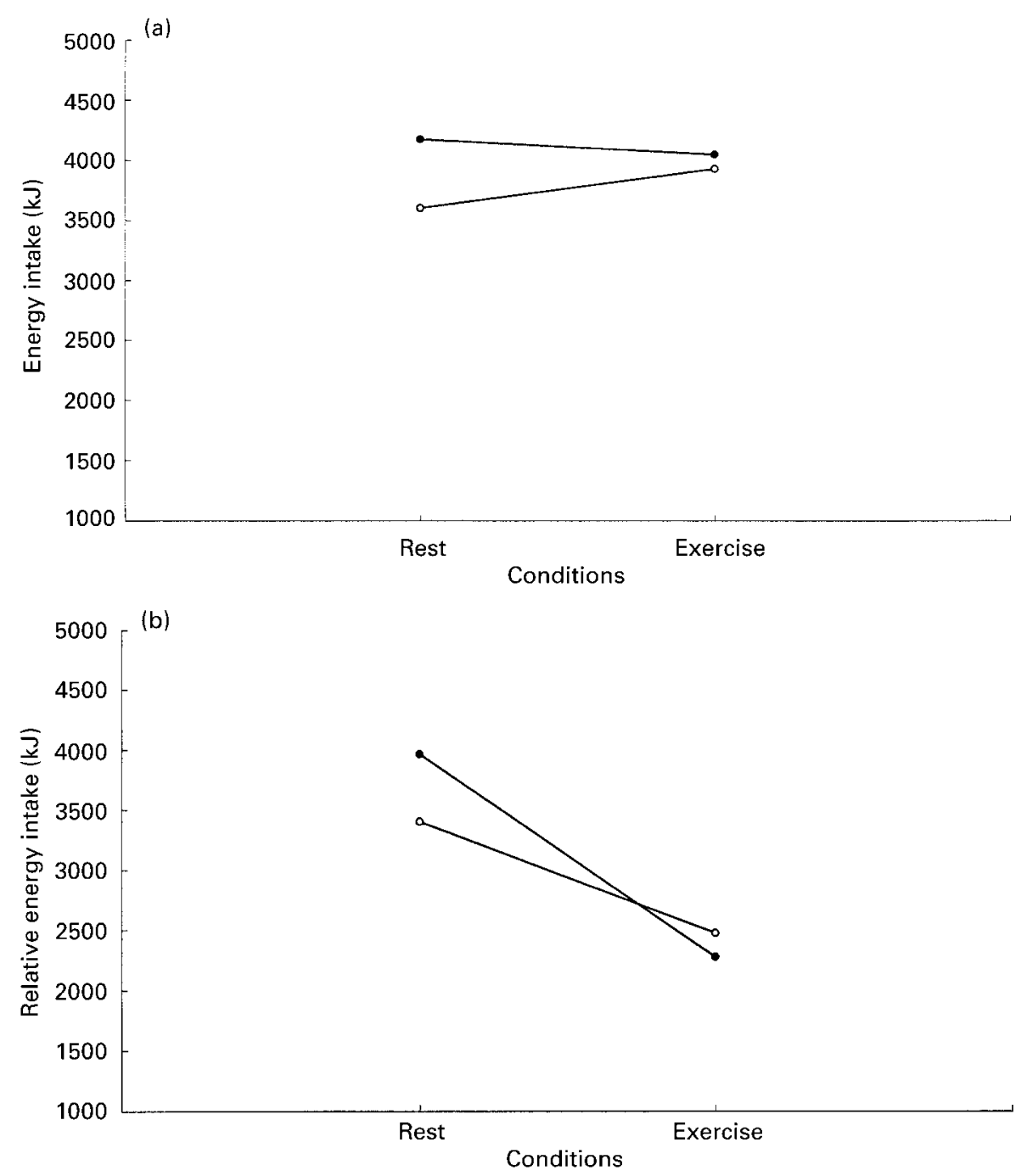

Fig. 2. Effect of exercise on (a) energy intake and (b) relative energy intake (average of low-fat and high-fat conditions) in twelve restrained (๑) and thirteen unrestrained $(O)$ eaters. Restraint scores were calculated using the Three Factor Eating Questionnaire (Stunkard \& Messick, 1985); restrained eaters scored $>10$ on the restraint scale. For details of low-fat and high-fat conditions see pp. 220-221. Relative energy intake=energy intake during the test meal - energy expenditure (measured during exercise session and estimated during rest session).

subjects ate less (g) during the high-fat conditions, whereas restrained subjects tended to eat similar amounts regardless of the condition. As expected, there was a significant effect of lunch type on fat $(F[1,23] 963 \cdot 2, P<0.001)$ and carbohydrate $(F[1,23] 903.5, P<0.001)$ intake when expressed as a percentage of energy intake.

\section{Post-lunch food hedonic ratings}

Post-lunch food hedonic ratings are shown in Table 3. Exercise significantly increased ratings of pleasantness, tastiness and palatability of the foods served at lunch $(F[1,23] 19.6, P<0.001 ; F[1,23] 11.5, P<0 \cdot 01 ; F[1,23]$

Table 3. Post-lunch food hedonic ratings $(\mathrm{mm})$ on each of the four experimental days in thirteen unrestrained $(U)$ and twelve restrained $(R)$ eaters* (Mean values and standard deviations)

\begin{tabular}{|c|c|c|c|c|c|c|c|c|c|c|c|c|c|c|c|c|}
\hline & \multicolumn{4}{|c|}{ Rest-LF } & \multicolumn{4}{|c|}{ Rest-HF } & \multicolumn{4}{|c|}{ Ex-LF } & \multicolumn{4}{|c|}{$\mathrm{Ex}-\mathrm{HF}$} \\
\hline & \multicolumn{2}{|c|}{$\mathrm{U}$} & \multicolumn{2}{|c|}{$\mathrm{R}$} & \multicolumn{2}{|c|}{$\mathrm{U}$} & \multicolumn{2}{|c|}{$\mathrm{R}$} & \multicolumn{2}{|c|}{$\mathrm{U}$} & \multicolumn{2}{|c|}{$\mathrm{R}$} & \multicolumn{2}{|c|}{$\mathrm{U}$} & \multicolumn{2}{|c|}{$\mathrm{R}$} \\
\hline & Mean & SD & Mean & SD & Mean & SD & Mean & SD & Mean & SD & Mean & SD & Mean & SD & Mean & SD \\
\hline Palatability (mm) & $73 \cdot 3$ & $22 \cdot 4$ & $70 \cdot 1$ & $16 \cdot 2$ & 71.9 & $16 \cdot 0$ & 83.7 & $15 \cdot 3$ & $77 \cdot 3$ & $15 \cdot 1$ & $76 \cdot 1$ & $13 \cdot 1$ & 78.5 & $15 \cdot 6$ & $84 \cdot 8$ & $15 \cdot 4$ \\
\hline Tastiness (mm) & $73 \cdot 8$ & $15 \cdot 5$ & 69.5 & $18 \cdot 1$ & $70 \cdot 8$ & $17 \cdot 6$ & $84 \cdot 1$ & $15 \cdot 2$ & 78.5 & $14 \cdot 1$ & $80 \cdot 1$ & $11 \cdot 0$ & $76 \cdot 4$ & $16 \cdot 0$ & $85 \cdot 1$ & $16 \cdot 0$ \\
\hline Pleasantness (mm) & $78 \cdot 6$ & $15 \cdot 7$ & $70 \cdot 9$ & 12.9 & $70 \cdot 8$ & $15 \cdot 9$ & 84.9 & $14 \cdot 6$ & 79.9 & $12 \cdot 5$ & 82.5 & $11 \cdot 1$ & $81 \cdot 2$ & $14 \cdot 6$ & $88 \cdot 2$ & $13 \cdot 3$ \\
\hline
\end{tabular}

Rest-LF, rest-low fat; Rest-HF, rest-high fat; Ex-LF, exercise-low fat; Ex-HF, exercise-high fat.

${ }^{*}$ Restraint scores were calculated using the Three Factor Eating Questionnaire (Stunkard \& Messick, 1985); restrained subjects scored >10 on the restraint scale. 
$8.9, P<0.01$ respectively). When correlation analyses controlling for the level of dietary restraint were performed, there was no relationship between these food hedonic ratings and energy intake or relative energy intake, in any of the four conditions. For pleasantness ratings, lunch type $\times$ group $(F[1,23] 5 \cdot 6, P<0.05)$ and lunch type $\times$ group $\times$ level of activity $(F[1,23] 4 \cdot 1, P=0.05)$ interactions were found. Post-hoc analyses showed that exercise enhanced the pleasantness of foods in the high-fat and low-fat conditions in unrestrained and restrained subjects respectively $(t 2.6$, d.f. $12, P<0.05 ; t 2.7$, d.f. $11, P<0.05$ respectively). In the rest-high fat condition, pleasantness ratings were significantly higher in restrained subjects than in unrestrained $(t 2 \cdot 3, P<0 \cdot 05)$.

\section{Discussion}

The absence of a compensation in energy intake in response to exercise in the present study is now well documented (for review see King, 1999), but is not in accordance with the predictions of Hill et al. (1995) that unrestrained eaters should increase their food intake. However, as previously suggested (Lluch et al. 1998), it is possible that energy intake was not measured for long enough and compensation could have taken place later. Although exercise failed to have any effect on energy intake in the two separate studies involving unrestrained and restrained females, comparisons between the two groups revealed a very interesting relationship between dietary restraint and energy intake. There was a positive correlation between dietary restraint and energy intake following a period of rest, but not after a bout of exercise. This relationship was independent of the nutrient manipulation (lunch type). The boundary model for the regulation of eating, in which the control of food intake is not between physiological but cognitive boundaries, has been proposed to explain that restrained eaters ate more after a high-energy preload than after a small preload or no preload (Herman \& Polivy, 1984). This phenomenon is known as 'counter-regulation' and has been linked to the concept of disinhibition: when the self-control of restrained eaters is disrupted, the loss of control leads to overeating and results in an increase of energy intake. Disrupting events, or disinhibitors, described in the literature include certain cognitions, alcohol and strong emotional states (Ruderman, 1986). In the present sample of restrained eaters, during the rest days, instead of reinforcing their level of dietary restraint (to maintain a control of their energy balance), it appeared that these females relaxed their control of food intake. Therefore, the rest condition (in which subjects were not allowed to exercise) could be considered as a disrupting event leading to the disinhibition of eating behaviour. Indeed, the role of physical activity in the control of body weight of the restrained subjects was confirmed from the debriefing questionnaire. Seven of the twelve subjects were more likely to use both exercise and dietary restraint to control their body shape or weight, two only exercise and three dietary restraint.

Another possible explanation of the positive correlation between dietary restraint and energy intake following a period of rest is that during the rest condition, subjects remained seated for $50 \mathrm{~min}$ in an individual room before being provided with their test lunch. This period gave them more opportunity to become preoccupied with thoughts about food. Previous studies (Rogers \& Hill, 1989; Jansen \& van den Hout, 1991; Federoff et al. 1997) have shown that pre-exposure to food cues originating from external sources (i.e. visual, olfactory or cognitive) has a significant impact on subsequent consumption, particularly for restrained eaters.

The present study also confirmed the phenomenon of 'passive overconsumption' (Blundell et al. 1995), that is, an increase in energy intake $(\mathrm{kJ})$ in the high-fat lunches despite a lower weight of food consumed. However, this phenomenon was not observed in the restrained subjects who ate a similar amount of food $(\mathrm{g})$, regardless of the condition (Lluch et al. 1998). This difference between the two groups supports the beliefs that restrained eaters stop eating not in response to satiety but because they have reached a cognitively-set limit which could be partly determined by the amount of food eaten.

In the present study, there were differences between restrained and unrestrained subjects in food hedonic ratings of the high-fat lunch observed following rest. The ratings were significantly higher in restrained individuals, a finding which has been previously reported in a snack study (Green \& Blundell, 1996). After exercise, there was a significant increase in the perception of the pleasantness, tastiness and palatability of the foods, independent of the degree of restraint. However, this effect was restricted to the highfat (low-carbohydrate) foods in unrestrained subjects and to high-carbohydrate (low-fat) foods in restrained eaters. This increase in the perceived pleasantness of the food after exercise was not observed in a similar study conducted in unrestrained males (King \& Blundell, 1995). However, previous work suggest that taste preferences vary as a function of dietary restraint and exercise (Kanarek et al. 1995).

If restrained eaters use exercise to control eating behaviour, it is possible they differ from unrestrained eaters in physiological characteristics and are physiologically fitter (higher $\mathrm{V}_{\mathrm{O}_{2} \text { max }}$ ). In our sample, dietary restrained subjects had a higher maximal $\mathrm{O}_{2}$ consumption than unrestrained subjects. Kanarek et al. (1995) found a positive relationship between dietary restraint and exercise, in terms of frequency. This finding has not been reported in two other studies (Klesges et al. 1992; Tepper et al. 1996). As excessive levels of physical activity may play a role in the development of eating disorders, the link between dietary restraint and the use of exercise as a means of controlling weight needs further work. In particular, young athletes who may be at risk of dietary restriction should be monitored (Ziegler et al. 1998).

In conclusion, this present study, comparing the shortterm effects of exercise and diet manipulations on energy intake in restrained and unrestrained females, showed some similarities and marked differences. In both restrained and unrestrained eaters, there is no energy compensation in response to an acute bout of exercise during the following meal. We hypothesise that in dietary restrained women who are regularly exercising, the combination of physical activity and a low-fat diet could be used advantageously to control appetite, prevent overconsumption and protect 
against the development of obesity. However, more research should focus on the examination of the psychological factors in the energy intake response to exercise, especially in the long-term.

\section{References}

Ainsworth BE, Haskell WL, Leon AS, Jacobs DR, Montoye HJ, Sallis JF \& Paffenbarger RS (1993) Compendium of physical activities: classification of energy costs of human physical activities. Medicine and Science in Sports and Exercise 25, $71-80$

Blundell JE, Burley VG, Cotton JR, Delargy HJ, Green SM, Greenough A, King NA \& Lawton CL (1995) The fat paradox: fat-induced satiety signals versus high fat overconsumption. International Journal of Obesity 19, 832-835.

de Castro JM (1995) The relationship of cognitive restraint to spontaneous food and fluid intake of free-living humans. Physiology and Behavior 52, 287-295.

Fedoroff IC, Polivy J \& Herman CP (1997) The effect of preexposure to food cues on the eating behavior of restrained and unrestrained eaters. Appetite 28, 33-47.

French SA, Jeffery RW \& Wing RR (1994) Food intake and physical activity: a comparison of three measures of dieting. Addictive Behaviors 19, 401-409.

Green SM \& Blundell JE (1996) Effect of fat- and sucrosecontaining foods on the size of eating episodes and energy intake in lean dietary restrained and unrestrained females: potential for causing overconsumption. European Journal of Clinical Nutrition 50, 625-635.

Herman CP \& Mack D (1975) Restrained and unrestrained eating. Journal of Personality 43, 647-660.

Herman CP \& Polivy J (1975) Anxiety, restraint and eating behavior. Journal of Abnormal Psychology 84, 666-672.

Herman CP \& Polivy J (1984) A boundary model for the regulation of eating. In Eating and its Disorders, pp. 141156 [AJ Stunkard and E Stellar, editors]. New York, NY: Raven Press.

Hill AJ \& Robinson A (1991) Dieting concerns have a functional effect on the behaviour of nine-year-old girls. British Journal of Clinical Psychology 30, 265-267.

Hill JO, Melby C, Johnson SL \& Peters JC (1995) Physical activity and energy requirements. American Journal of Clinical Nutrition 62, Suppl., 1059S-1066S.

Jansen A \& van den Hout M (1991) On being led into temptation: "Counterregulation"' of dieters after smelling a preload. Addictive Behaviors 16, 247-253.

Kanarek BB, Ryu M \& Przypek J (1995) Preferences for foods with varying levels of salt and fat differ as a function of dietary restraint and exercise but not menstrual cycle. Physiology and Behavior 57, 821-826.

King NA (1999) What processes are involved in the appetite response to moderate increases in exercise-induced energy expenditure? Proceedings of the Nutrition Society 58, 107-113.

King NA \& Blundell JE (1995) High-fat foods overcome the energy expenditure induced by high-intensity cycling or running. European Journal of Clinical Nutrition 49, 114-123.

King NA, Snell L, Smith RD \& Blundell JE (1996) Effects of short-term exercise on appetite responses in unrestrained females. European Journal of Clinical Nutrition 50, 663-667.

King NA, Tremblay A \& Blundell JE (1997) Effects of exercise on appetite control: implications for energy balance. Medicine and Science in Sports and Exercise 29, 1076-1089.

Klesges RG, Isbell TR \& Klesges LM (1992) Relationship between dietary restraint, intake, physical activity and body weight: a prospective analysis. Journal of Abnormal Psychology 101, 668-674.

Laessle RG, Tuschl RJ, Kotthaus BC \& Pirke K-M (1989) Behavioral and biological correlates of dietary restraint in normal life. Appetite 12, 83-94.

Lluch A, King NA \& Blundell JE (1998) Exercise in dietary restrained women: no effect on energy intake but change in hedonic ratings. European Journal of Clinical Nutrition 52, 300-307.

Rogers PJ \& Hill AJ (1989) Breakdown of dietary restraint following mere exposure to food stimuli: Interrelationships between restraint, hunger, salivation, and food intake. Addictive Behaviors 14, 387-397.

Ruderman AJ (1986) Dietary Restraint: a theoretical and empirical review. Psychological Bulletin 99, 247-262.

Storer TW, Bunnell TJ, Hand A \& Grant S (1995) Validation of a new metabolic measurement cart. International Journal of Sports Medicine 16, 101.

Stunkard AJ \& Messick S (1985) The Three-Factor Eating Questionnaire to measure dietary restraint, disinhibition and hunger. Journal of Psychosomatic Research, 29, 71-83.

Tepper BJ, Trail AC \& Shaffer SE (1996) Diet and physical activity in restrained eaters. Appetite 27, 51-64.

Tuschl RJ, Platte P, Laessle RG, Stichler W \& Pirke K-M (1990) Energy expenditure and everyday eating behavior in healthy young women. American Journal of Clinical Nutrition 52, $81-86$

van Strien T, Frijters JER, van Staveren WA, Defares PB \& Deurenberg P (1986) The predictive validity of the Dutch restrained eating scale. International Journal of Eating Disorders 5, 747-755.

Wardle J \& Beales S (1987) Restraint and food intake: an experimental study of eating patterns in the laboratory and in normal life. Behaviour Research and Therapy 25, 179-185.

Wardle J, Marsland L, Sheikh Y, Quinn M, Fedoroff I \& Ogden J (1992) Eating style and eating behaviour in adolescents. Appetite 18, 167-183.

Ziegler P, Hensley S, Roepke JB, Whitaker SH, Craig BW \& Drewnowski A (1998) Eating attitudes and energy intakes of female skaters. Medicine and Science in Sports and Exercise 30, 583-586. 